Sante De Sanctis le origini dela neuropsichiatria infantile nell'Universitá di Roma: la dementia praecocíssima

Morgese, G., \& Lombardo, G. P.

Roma, IT: Sapienza Universitá Editrice, 2017, 194 págs.

\title{
A infância pelo olhar da psiquiatria na Itália do início do século XX: Sante De Sanctis
}

Childhood through the eyes of psychiatry in Italy at the beginning of the 20 ${ }^{\text {th }}$ century: Sante De Sanctis

Nesse livro mergulhamos nas origens da neuropsiquiatria infantil na Itália, por meio da obra de Sante De Sanctis (1862-1935), autor que contribuiu para a formação do campo da neuropsiquiatria como disciplina autônoma, e um de seus fundadores. A importância dessa obra deriva, dentre outras razões, da escassez de estudos históricos sobre o percurso científico e institucional da neuropsiquiatria infantil. O livro é produto do Laboratório de História da Psicologia, da Università di Roma Sapienza (Lombardo \& Morgese, 2017).

${ }^{* 1}$ Universidade Estadual da Paraíba - UEPB (Campina Grande, PB, Brasil). 
A introdução contém uma apresentação da trajetória de De Sanctis, médico, e figura de interesse para a história da psicologia e da psiquiatria, especialmente na Itália. $\mathrm{O}$ autor obteve projeção destacada em seu país, e reconhecimento em outros países, incluindo o Brasil. Foi catedrático de Psicologia Experimental e de Clínica das Doenças Nervosas e Mentais na Universidade de Roma Sapienza. Contribuiu para a construção de uma concepção de neuropsiquiatria infantil que ultrapassasse as noções fundamentadas em argumentos biológicos, consensualmente estabelecidas no contexto científico da época, marcados pela antropologia positivista, destacando-se influências de Morel (1809-1873) e Lombroso (1835-1909).

O primeiro capítulo apresenta uma reconstrução do contexto psiquiátrico italiano do final do século XIX e início do século XX, período em que há um esforço para a formulação de classificação para as doenças mentais e para a criação de legislação que estabelecesse o trato oficial com a loucura. Na Itália, essa lei será efetivamente promulgada em 1904 e permanecerá em vigor até 1978. Esta não fazia menção à infância, e não havia uma lei específica para tal. As primeiras instituições destinadas à infância foram inauguradas no final do século XIX, e buscavam tratar crianças consideradas degeneradas, com 878 tendências criminais. Em 1899, De Sanctis fundou um asilo-escola para a assistência de crianças consideradas anormais.

A criação de instituições para a infância veio no bojo de uma transformação da sua concepção. Passa a ser esquadrinhada, com medidas antropométricas e testes psicológicos. O desenvolvimento da psiquiatria infantil se deu em contexto de formação do Estado Moderno e defesa social, com necessidade crescente de controle sobre os indivíduos.

O segundo capítulo aborda a educabilidade da infância considerada anormal. De Sanctis, nos estudos da inteligência, dispensa medidas antropométricas e desenvolve um teste psicológico de inteligência, os Reativos de De Sanctis, para definir o grau de deficiência intelectual entre grave, médio e leve. Defendia a importância de estabelecer diagnóstico, prognóstico e consequente tratamento para a infância, com programa educativo individual. A escola deveria ser um espaço para contrabalançar a anomalia hereditária. $\mathrm{O}$ ambiente seria elemento mais importante para o prognóstico que as determinações biológicas.

No capítulo 3 há uma incursão ao diagnóstico de dementia praecocissima definido por De Sanctis, e sua relação com a classificação nosográfica do período. Em 1906, o autor define esse diagnóstico como uma condição psicopatológica com sintomas de incoerência afetiva; estranheza de humor, 


\section{RESENHAS BIBLIOGRÁFICAS}

comportamento e expressão; tendência a falar, rir e gesticular sozinho; linguagem incoerente e estereotipias verbais. Esse diagnóstico se aproxima ao de demência precoce de Emil Kraepelin (1856-1926), com o diferencial de ter início na infância. Foi reconhecido em território nacional e internacional, sendo utilizado em hospitais psiquiátricos na Itália.

No quarto capítulo há uma análise da institucionalização e reconhecimento acadêmico da neuropsiquiatria infantil na Itália, que ocorre após a Segunda Guerra Mundial, em um processo no qual Carlo De Sanctis (1888-1973) e Giovanni Bollea (1913-2011) tiveram papel de relevância. Os autores viam a educabilidade de De Sanctis, vinculada à família e ao ambiente, e o asilo-escola, instituição que De Sanctis defendia, como importante recurso se direcionado também à educação dos pais.

Ao final do livro, estão publicados três textos de autoria de Sante De Sanctis, relevantes para compreender a sua concepção de neuropsiquiatria infantil e da demência precocíssima. Sendo: "Sopra alcune varietà dela demenza precoce", de 1906; "La neuropsichiatria infantile", de 1923; e, um capítulo de Neuropsiquiatria infantil, publicado em 1925, intitulado "Demenza precoce infanto-puerile (demenza precocíssima o schizofrenia prepuberale)".

A publicação de Morgese e Lombardo (2017) é uma obra completa que aborda as origens da neuropsiquiatria infantil na Itália, reconstruindo o contexto intelectual e institucional do período, da Itália e Europa, sobre infância, loucura, deficiência intelectual e educação, e apresentam de forma cuidadosa um intelectual com inúmeras contribuições no campo da psicologia e da psiquiatria.

A obra aponta para a compreensão da produção de uma concepção de infância anormal, digna de estudos científicos pela psiquiatria, psicologia e pedagogia. Infância que se torna objeto de estudos e de assistência. Pode-se ver semelhanças com o contexto brasileiro. Influências teóricas presentes no cenário italiano tornaram-se relevantes para compreender a produção intelectual brasileira do fim do século XIX e início do século XX. Fatores como a formação do Estado Moderno, e a relevância que a infância assume, também estão presentes no Brasil desse período (Ribeiro, 2003). Neste sentido, a obra serve de guia para uma compreensão das origens históricas da neuropsiquiatria infantil. E oferece a oportunidade de ler importantes textos de De Sanctis relacionados à área. 


\section{Referências}

Lombardo, G. P., \& Morgese, G. (2017). Fare e divulgare la ricerca storica: il laboratorio e l'archivio online di storia della psicologia della "Sapienza" Università di Roma. Memorandum, 33, 37-50.

Morgese, G., \& Lombardo, G. P. (2017). Sante De Sanctis le origini dela neuropsichiatria infantile nell'Università di Roma: la dementia praecocissima. Roma, IT: Sapienza Università Editrice.

Ribeiro, P. R. M. (2003). A criança brasileira nas primeiras décadas do século XX: a ação da higiene mental na psiquiatria, na psicologia e na educação. In M. L. Boarini, Higiene e raça como projetos: higienismo e eugenismo no Brasil. Maringá, PR: Eduem.

Citação/Citation: Cunha, C. C. (2020, dez.). A infância pelo olhar da psiquiatria na Itália no início do século XX: Sante De Sanctis. Resenha do livro Sante De Sanctis le origini dela neuropsichiatria infantile nell'Università di Roma: la dementia praecosiccima. Revista Latinoamericana de Psicopatologia Fundamental, 23(4), 877-880. http://dx.doi.org/10.1590/ 1415-4714.2020v23n4p877.12.

Editora/Editor: Profa. Dra. Marta Regina de Leão D’Agord

Submetido/Submitted: 13.11.2020 / 11.13.2020 Aceito/Accepted: 15.11 .2020 / 11.15.2020

Copyright: (C) 2009 Associação Universitária de Pesquisa em Psicopatologia Fundamental/ University Association for Research in Fundamental Psychopathology. Este é um artigo de livre acesso, que permite uso irrestrito, distribuição e reprodução em qualquer meio, desde que o autor e a fonte sejam citados / This is an open-access article, which permits unrestricted use, distribution, and reproduction in any medium, provided the original authors and sources are credited.

\section{Carolini Cássia Cunha}

Docente da Universidade Estadual da Paraíba - UEPB (Campina Grande, PB, Brasil); Doutora em Psicologia pela Universidade Federal do Rio de Janeiro - UFRJ (Rio de Janeiro, $\mathrm{RJ}, \mathrm{Br})$.

Rua João da Silva Pimentel, 391

58401-282 Campina Grande, PB, Br

carol_ccunha@yahoo.com.br

https://orcid.org.0000-0003-4008-7246

This is an open-access article, which permits unrestricted use, distribution, (cc) BY-NC and reproduction in any medium for non-commercial purposes provided the original authors and sources are credited. 